IZA DP No. 1152

Choosing the J oneses:

Endogenous Goals and Reference Standards

Armin Falk

Markus Knell

May 2004 


\title{
Choosing the Joneses: Endogenous Goals and Reference Standards
}

\author{
Armin Falk \\ IZA Bonn, University of Bonn, \\ University of Zurich \\ Markus Knell \\ Austrian National Bank \\ Discussion Paper No. 1152 \\ May 2004 \\ IZA \\ P.O. Box 7240 \\ 53072 Bonn \\ Germany \\ Phone: +49-228-3894-0 \\ Fax: +49-228-3894-180 \\ Email: iza@iza.org
}

Any opinions expressed here are those of the author(s) and not those of the institute. Research disseminated by IZA may include views on policy, but the institute itself takes no institutional policy positions.

The Institute for the Study of Labor (IZA) in Bonn is a local and virtual international research center and a place of communication between science, politics and business. IZA is an independent nonprofit company supported by Deutsche Post World Net. The center is associated with the University of Bonn and offers a stimulating research environment through its research networks, research support, and visitors and doctoral programs. IZA engages in (i) original and internationally competitive research in all fields of labor economics, (ii) development of policy concepts, and (iii) dissemination of research results and concepts to the interested public.

IZA Discussion Papers often represent preliminary work and are circulated to encourage discussion. Citation of such a paper should account for its provisional character. A revised version may be available on the IZA website (www.iza.org) or directly from the author. 


\title{
ABSTRACT \\ Choosing the Joneses: Endogenous Goals and Reference Standards*
}

\begin{abstract}
A growing economic literature stresses the importance of relative comparisons, e.g., for savings and consumption or happiness. In this literature it is usually assumed that reference standards against which people compare themselves are exogenously given. In contrast findings from social psychology suggest that people play an active role in determining their reference standards. We present a social comparison model where people choose their reference standards to serve motives of self-improvement and self-enhancement. The model predicts that reference standards increase in individuals' abilities and that thus people tend to compare themselves to similar others. The results of a questionnaire study confirm the model's prediction.
\end{abstract}

JEL Classification: D62, D63, H31, Z13

Keywords: reference standard, goals, social comparison, happiness

Corresponding author:

Armin Falk

IZA Bonn

P.O. Box 7240

53072 Bonn

Germany

Email: falk@iza.org

\footnotetext{
* We would like to thank Samuel Bowles, Urs Fischbacher, Simon Gächter, Lorenz Goette, Armin Schmutzler and two anonymous referees for valuable comments. The first author acknowledges support from the MacArthur Foundation (Network on Economic Environments and the Evolution of Individual Preferences and Social Norms). The views expressed in this paper do not necessarily reflect the opinion of the Österreichische Nationalbank.
} 


\section{Introduction}

People compare themselves to others - always and everywhere. And they compare almost everything: their wages, their cars, their grades and their health status, how many friends they have and how fast they can run. The importance of these comparisons for economics is without any doubt. Robert Frank, for example, has noted that "without taking people's concerns about relative standing into account, economists have been led to adopt a variety of theories that seem either utterly implausible as descriptions of human behavior or sharply at variance with observed facts" (Frank, 1985, p. 38). Clark and Oswald (1996) have provided convincing empirical evidence indicating that a person's perception of subjective well being and happiness does not only depend on absolute but also relative income. Further economic research on relative comparison includes studies on savings and consumption behavior (Carroll, 1998; Frank 1985), labor supply (Boskin and Sheshinski, 1978; Neumark and Postlewaite, 1998), the behavior of financial markets (Campbell and Cochrane, 1999) and on inequality and growth (Cooper and Garcia-Penalosa, 1999; Knell, 1999).

In most existing models of relative comparison three assumptions are made. First, utility is defined not only in terms of an individual's absolute performance, e.g., income $c$, but also in terms of the performance relative to a reference group or reference standard $r$, i.e., $U=U(c, r)$. Second, utility is increasing in the level of $c$ and decreasing in the level of $r$, i.e., $\partial U / \partial c>0$ and $\partial U / \partial r<0$. Third, the reference standard $r$ is assumed to be exogenously given and it is often assumed that $r$ is the same for all people in a given environment. This third assumption is problematic for two reasons. First, it is at odds with findings from social psychology according to which reference standards are to some extent actively chosen. In this literature it is emphasized that people take an active role "consciously selecting comparison targets from a wide array of available others in order to meet varying goals" (Diener and Fujita, 1997, p. 330). Second, in modeling the reference standard as exogenously given there is little guidance for the researcher on how to specify the determinants of $r$. It remains, e.g., unclear whether $r$ should be assumed to be the same for everybody or different from individual to individual and how a possible heterogeneity of reference standards could be justified and modeled. This might be part of the reason why the social comparison literature is frequently criticized. In this paper we therefore present a social comparison model with endogenous reference standards, i.e., in our model 
people do not only try to keep up with but also choose their Joneses in a systematic and predictable way.

In modeling the choice of $r$ we closely follow the arguments put forward in the social psychology literature. In particular we assume that in choosing $r$ people are guided by the motives of self-enhancement and self-improvement (Wood and Taylor 1991). Self-enhancement refers to the fact that people compare to others in order to make themselves feel better. They therefore compare downward, i.e., they compare themselves with others who, e.g., perform poorer, are less fortunate or have a lower income or health status. If self-enhancement were the only relevant motive in the comparison process we should see that people would always choose $r$ as low as possible. But self-enhancement is only part of the story. Equally important is the motive of self-improvement, which means that people compare themselves to improve their performance. In fact there is a large body of evidence indicating that people perform better if they compare themselves with others who are more sucessful. Thus performing upward comparisons has an indirect positive effect on overall utility since it facilitates performance.

Choosing the reference standard optimally implies balancing the two motives of self-enhancement and self-improvement. In our model a person's individual abilities are decicive for the optimal level of $r$. In particular, the optimal reference level increases in one's own abilities. The intuition for this result is that while people want to motivate themselves they do not like to fall behind their reference groups too much. The fact that $r$ increases in one's abilities implies that individuals have different reference groups and that people select reference groups whose performance level is not too different from their own. In this sense our model formulates a rationale for the assumption that people compare themselves to similar others. ${ }^{1}$

The model's conclusion that $r$ increases in abilities is a testable prediction. We test this prediction in the context of intellectual performance. In a questionnaire study students from the University of Zurich were asked to indicate their aspired diploma degree as a measures of their reference standard. As a proxy for their abilities we take their high school grades. Controlling for socio-economic characteristics and related questions from the General Social Survey (GSS), we show that in line with our model students with higher abilities have higher reference levels. We also find that female students have significantly lower reference standards than male students and that

\footnotetext{
${ }^{1}$ For a different approach based on sorting, see Frank (1985).
} 
people who think that ambitions are important to get ahead select higher reference standards.

We also discuss how the fact that reference standards are actively chosen affects behavior and perceptions in different economically relevant contexts. We show that the choice of reference standards depends on the importance of relative comparison, which prevails in a given environment. Then we show that our model helps understanding empirical regularities that are hard to reconcile with either a standard neoclassical model or a model with exogenous reference standards. In particular we address the importance of coping strategies in the context of theories of migration and happiness studies.

The paper is structured as follows. In section 2 we derive the formal model. In section 3 we show that the model predicts that reference standards increase in a person's abilities. This hypothesis is empirically tested and confirmed. Section 4 discusses implications of our model in economically relevant contexts such as migration and social stability and perceptions of happiness. Section 5 concludes.

\section{Modeling the social comparison process}

\subsection{The basic ideas}

The existing economic literature on social comparison treats reference standards as exogenously determined (e.g., Boskin and Sheshinski, 1978; Easterlin, 1974, 1995). Contrary to this 'forced' comparison conception many social psychologists have emphasized the fact that reference standards are actively chosen (e.g., Wood and Taylor 1991). This 'coping approach' (Diener and Fujita 1997) stresses the flexibility of people to use social information and it refers to the instrumental usage of comparison targets to serve self-relevant goals. Note that the coping approach stresses the endogenity of reference groups but does not say that the choice of reference standards is completely unrestricted. The extent to which reference groups are endogenously determined depends on the specific dimension of comparison, the availability of information and the pervasiveness and transparency of environmental factors (Diener and Fujita, 1997).

Given that people choose referent others with whom they wish to compare with, the immediate question is: to what end? What are the self-relevant goals that are 
pursued in the process of selecting reference groups or standards? Two of the most important goals studied in the social comparison literature are "self-improvement" and "self-enhancement" (see, e.g., Wood and Taylor, 1991 and the references cited there $\left.^{2}\right)$.

Self-enhancement refers to the fact that comparing to others who are inferior often makes us feel better. For reasons of self-enhancement, people engage in 'downward comparison' (Wills, 1981), i.e., they compare with others who are inferior or less fortunate. As a consequence of using downward comparisons people see themselves as highly talented and underestimate others' talents (Campbell 1986, Marks 1984). There is a large body of empirical evidence indicating that downward comparison enhances moods and subjective well-being (see, e.g., Brown and Dutton, 1995; Taylor, Wood and Lichtman, 1983). Downward comparison as a coping strategy has shown to be of particular importance for people who suffer from major medical problems (see Affleck and Tennen, 1991). Summarizing the empirical evidence Wood and Taylor (1991) conclude that "[w]hen one has an unfavorable characteristic, one may self-enhance by reminding oneself of others who are similarly flawed. Even better is a downward comparison - someone who possesses even more of the undesirable characteristic" (p. 31). In terms of a social comparison model, downward comparison is equivalent to choosing a relatively low reference standard. This improves utility since the latter enters negatively into the utility function.

If self-enhancement would be the only motive to select reference standards, one would expect that everybody compares downward. However, reference standards are also selected to serve the purpose of self-improvement. Self-improvement describes the fact that people perform better and are more successful if they set themselves high goals or compare with high reference standards. For reasons of self-improvement people compare themselves upward, i.e., the comparison group consists of people who perform better or are more fortunate (Wood and Taylor, 1991 p. 27). The idea that upward comparison motivates and enhances performance is probably familiar to everybody $^{3}$. This intuition has been supported in social psychology. In laboratory

\footnotetext{
${ }^{2}$ We use the terms "self-improvement" and "self-enhancement" in the way they are introduced in the corresponding social psychological literature. Note, however, that according to common language usage both terms sound very much alike and may therefore produce misunderstandings.

${ }^{3}$ To quote two examples: "We aim above the mark to hit the mark." (Ralph Waldo Emerson, writer). "Unless you have some goals, I don't think there's any way to get above the pack. My vision was always well beyond what I had any reason to expect." (John "Frenchy" Fuqua, running
} 
experiments it has been shown that performance of a particular task is improved in the presence of someone who does the task better or is more successful (Seta, 1982; Bandura, 1986). Summarizing their review of empirical research on self-improvement, Major, Testa and Bylsma (1991) point to "the beneficial consequences of exposure to upward comparisons, especially with similar others, in situations where improved performance is perceived as possible. Under these conditions upward comparisons raise perception of self-efficiacy and motivate task persistence" (p. 252).

\section{$2.2 \quad$ A Simple Model}

According to the above discussion a utility function should capture the following features:

- Utility depends on the absolute outcome and on the relative outcome, i.e., on the outcome relative to some reference standard.

- The extent to which the reference standard is endogenously selected is restricted by environmental factors, i.e., the reference standard is partly endogenous and partly exogenous.

- The endogenous component of the reference standard is chosen to accomplish the goals of self-enhancement and self-improvement.

In the following we work with a utility function of the following form:

$$
U_{i}=U\left(c_{i}, r_{i}\left(x, g_{i}\right), k\left(e_{i}, g_{i}\right)\right)
$$

The utility of individual $i$ increases in the level of absolute outcome $c_{i}$ and decreases in the size of the reference standard $r_{i}$, just as assumed in standard social comparison models. Different to the latter ones, however, $r_{i}$ is composed of an exogenous component $x$ and an actively chosen component $g_{i}$. Utility is negatively affected by the costs of producing outcome $k$, which are assumed to increase in the provided effort $e_{i}$ and decrease in the level of $g_{i}$, indicating that an individual perceives the same level of effort as less painful if he or she works for high goals. This formulation thus takes account of the positive motivational effects of goal-setting. The utility function back). 
(1) is maximized with respect to a standard production function $c_{i}=f\left(e_{i}\right)$. Taken together this framework represents a standard comparison model plus the actively chosen goal, $g_{i}$, which is chosen to serve the goals of self-enhancement (low $g_{i}$ in $r_{i}$ ) and self-improvement (high $g_{i}$ in $k$ ).

An alternative way to translate the psychological theory of self-improvement and self-enhancement into a formal framework would be to argue that goals do not lower the costs of exerting effort but rather lead to a higher output for a given level of effort. Thus one could define the problem as the maximization of $U_{i}=U\left(c_{i}, r_{i}\left(x, g_{i}\right), e_{i}\right)$ subject to $c_{i}=f\left(e_{i}, g_{i}\right)$. In fact, this formulation is the mirror (or "dual") image to (1) and leads to identical results for appropriately chosen functional forms. In our opinion the version with cost-reducing effects of goal-setting is somewhat closer to the psychological literature and in the following we will build on this framework.

Setting up the Lagrangian of the problem, maximizing with respect to $c_{i}, e_{i}, g_{i}$ and $\lambda$ (the Lagrangian multiplier) and eliminating the latter leads to the following conditions that a solution has to fulfill ${ }^{4}$ : (i) $u_{k} k_{e}=-u_{c} f_{e}$, (ii) $u_{r} r_{g}=-u_{k} k_{g}$ and the budget constraint $c=f$. In the following we want to present a particularly simple specification of this formal model that allows us to discuss the logic of the set-up and the crucial issues in a straightforward manner.

We assume that the utility function can be written as $U_{i}=\alpha \ln \left[(1-\theta) c_{i}+\theta\left(c_{i}-r_{i}\right)\right]-$ $\beta \ln \left[k\left(e_{i}, g_{i}\right)\right]$. This means that the absolute outcome $c_{i}$ and the outcome relative to the reference standard $\left(c_{i}-r_{i}\right)$ contribute in a linear way to an individual's utility. The reference standard $r_{i}$ is also assumed to be a linear combination of the exogenously given standard $x$ and the actively chosen component $g_{i}$, where the weight of the latter is given by $q$, i.e., $r_{i}=(1-q) x+q g_{i}$. For the costs of effort we assume that $k\left(e_{i}, g_{i}\right)=\frac{B}{\left(g_{i}^{\gamma}\right)^{\delta}\left(1-e_{i}\right)^{1-\delta}}$. Here $0 \leq e_{i} \leq 1$ is the chosen effort (or labor) supply and $B$ is a constant. The parameter $\delta$ measures the importance of self-improvement. The costs of effort thus increase in $e_{i}$ and decrease in $g_{i}$. The same amount of effort is thus perceived as less cumbersome if the chosen reference standard is higher. Furthermore we assume that $\gamma \equiv \theta q$. This means that the positive motivational effect of setting a high $g_{i}$ disappears when $\theta=0$ or when $q=0$, i.e., when comparisons play no role or when there is no scope for actively determining the reference standard. The

\footnotetext{
${ }^{4}$ Here $z_{y}$ stands for the partial derivative of $z$ w.r.t. $y$.
} 
production function is finally given by:

$$
c_{i}=a_{i} e_{i}
$$

where $a_{i}$ is the ability of individual $i .^{5}$

We can combine these assumptions to arrive at the following representation of utility for individual $i:^{6}$

$$
u_{i}=\alpha \ln \left(c_{i}-\theta(1-q) x-\theta q g_{i}\right)+\beta(1-\delta) \ln \left(1-e_{i}\right)+\theta q \beta \delta \ln \left(g_{i}\right)
$$

Individual $i$ maximizes (3) with respect to $c_{i}, g_{i}$ and $e_{i}$ and subject to the production function (2). We assume that there exists a continuum of individuals indexed by $i \in[0,1]$ that differ with respect to their ability $a_{i}$ which is drawn from some distribution. ${ }^{7}$ The variable $x$ represents the exogeneous part of the reference standard that is beyond the control of individual $i$. It might stand, e.g., for a (physiologically defined) subsistence level, a given requirement level (at school or at the job), for standards imposed by parents, friends and neighbors or for the individual's own past achievements (as it is assumed in habit formation models). ${ }^{8}$ Under all of these assumptions $x$ is independent of the contemporaneous performance level of the other individuals.

Alternatively one could assume, however, that $x$ is the average achievement of the people acting in $i$ 's social environment, i.e., $x=\bar{c}$ and $\bar{c}=\int_{i=0}^{1} c_{i}^{*}(\bar{c}) \mathrm{d} i$. In other words, in equilibrium it holds that the aggregated optimal performance decisions $c_{i}^{*}$ add up to $\bar{c}$ on which the optimal decisions are based. This is an assumption that is frequently made in social comparison models in order to capture the interactive nature of comparisons. According to this specification higher performance of others increases an individual's reference standard. Since individual utility decreases in $\bar{c}$ there is a negative performance or consumption externality (c.f., for example, "grading on the curve" or "consumption rat races" etc.). Due to the large number of individuals in

\footnotetext{
${ }^{5}$ The above-mentioned "dual" equivalent of this formulation would amount to: $U_{i}=\alpha \ln \left(c_{i}-\right.$ $\left.\theta r_{i}\right)-\beta \ln \left(e_{i}\right)$ with a production function: $c_{i}=a_{i}\left[1-\frac{B}{e_{i}^{1-\delta} g_{i}^{\gamma \delta}}\right]$.

${ }^{6}$ Note that thereby we use the monotonic transformation: $u_{i}=\ln U_{i}$ and leave out the constant $-\beta \ln B$.

${ }^{7}$ We assume throughout the paper that the ability distribution is sufficiently compressed, i.e., $a_{i} \geq \tilde{a}, \forall i$ (where $\tilde{a}$ is defined in the appendix). This assumption guarantees that in equilibrium $c_{i}-\theta r_{i} \geq 0$ and $g_{i} \geq 0$.

${ }^{8}$ In this case we would have to "individualize" this part and write $x_{i}$.
} 
our model and to the fact that they are assumed to move simultaneously individual $i$ disregards the effect of its own decision on $\bar{c}$. In the following we will mainly focus on this case where $x=\bar{c}$ since this directly allows us to relate our results to the ones of the forced comparison literature. For the general conclusions that are derived later it does not (qualitatively) matter, however, which specification of $x$ is chosen.

Our framework includes two special models as nested cases: the forced comparison model and the standard neoclassical model. If $q=0$ all comparison is forced and the reference standard is solely determined by the environment, given by $\bar{c}$ (or by $x$ ). If, on the other hand, $\theta=0$ holds then comparisons play no role and we are back to the typical neoclassical model. For all cases where relative comparison matters $(\theta>0)$ and where individuals play an active role in determining their comparison targets $(q>0)$ we can study the endogenous determination of the reference standards. This is done in the next section.

\section{$3 \quad$ Reference Standards and Abilities}

Our model yields several interesting implications for how people optimally select their goals and reference standards depending on their own personal characteristics and on a number of environmental factors that determine, e.g., the relative importance of self-enhancing and self-improving motives. In this section we want to focus specifically on the interpersonal aspects and analyze the influence of individual abilities on goalsetting. Our main result is stated in the following proposition. ${ }^{9}$

Proposition 1 For $q>0$ the actively chosen component of a person's reference standard $g_{i}^{*}$, the total reference standard $r_{i}^{*}$ and the outcome $c_{i}^{*}$ are increasing in the person's ability $a_{i}$, i.e., $\frac{\partial g_{i}^{*}}{\partial a_{i}}>0, \frac{\partial r_{i}^{*}}{\partial a_{i}}>0$ and $\frac{\partial c_{i}^{*}}{\partial a_{i}}>0$.

According to Proposition 1 people with high abilities have high goals and reference standards whereas people with lower abilities select low standards of comparison. The intuition is simple: People with high abilities set themselves high goals (i.e., they compare themselves with 'richer', 'faster', 'smarter' and generally more successful people) in order to motivate themselves. Even though this has a negative effect in terms of self-enhancement, they can 'afford' to set goals because — given their high

\footnotetext{
${ }^{9}$ The proofs are collected in the appendix.
} 
abilities - they will end up reaching relatively high outcomes. People with low abilities on the other hand do not select high reference standards since they would never come close and would experience a large disutility from inferior achievements. Thus, the optimal reference standard for a given ability just balances the tradeoff between the two goals of self-enhancement and self-improvement. For $q=0$ there is no choice to make anymore and all people have the same reference standard $\bar{c}$ independent of their abilities. The fact that reference standards are positively correlated with abilities implies that people compare themselves with similar others, in the sense that people with high abilities have higher reference standards and groups than people with low abilities. Thus the model gives a rationale for the frequently made assumption that people compare themselves with similar others. ${ }^{10}$

In the following we empirically test Proposition 1 in the context of intellectual achievements. For this purpose we have conducted a questionnaire study with 255 students from the University of Zurich and the Polytechnical University of Zurich that allows us to explore whether students with higher abilities set themselves higher reference standards. ${ }^{11}$ The students were invited to a computer lab where they were given short instructions and the questionnaire. They received a small show-up fee for coming.

The two central questions asked are about (i) students' aspired grade on the final university examination and (ii) students' high-school grade. The first variable is our measure of students' goals, i.e., the actively chosen component $g_{i}$. It is the grade of students' "final university examination", which is taken at the end of the first-degree university study. ${ }^{12}$ The grades are numbers which are in the range from 1 to 6 in steps of .25. In order to pass the university examination students require at least a grade

\footnotetext{
${ }^{10}$ For the assumption $x=\bar{c}$ the achievements $\left(c_{i}\right)$ of all individuals enter the reference standard. Nevertheless it is suggestive to assume that people associate their total reference standard $r_{i}$ with the achievement of a certain specific individual. Since $r_{i}$ increases in ability this implicit reference group is positively correlated with ability.

${ }^{11}$ In the same questionnaire study we have also asked students whether they try harder if they have set themselves high goals. This was meant to investigate whether (self-improving) upward comparisons have in fact motivational power. Possible answers range from 1 (= do not agree at all) to 5 (= totally agree). About 80 percent of all students indicated that having high goals improves their own effort (categories 4 and 5). Only 10 percent did not agree. This result lends further support for the motivational structure behind our model.

${ }^{12}$ This degree is called "Lizentiat", which Swiss students typically take at an age of about 25.
} 
of 4.0. The grade 5.0 is "good", 5.5. is "very good" and 6.0 is "excellent". Notice that we did not ask students about their expected grades. Rather we explicitly asked them to indicate their aspired examination grade. In our sample the mean value of the aspired degree is 4.80 (std. dev.: 0.37). The second variable "high-school graduation grade" is our proxy for a student's intellectual abilities (mean value is 4.77 , std. dev. is 0.39$)$. The rationale to use this variable as an indicator for ability is the fact that on average better grades are correlated with the ability to get a good diploma grade. ${ }^{13}$ As the grade on the final university examination the high-school graduation grade is a number between 1 and 6 .

Given that the latter grade is an appropriate measure of a student's abilities we should - according to Proposition 1 - find a positive correlation between aspired final university examination grade and the high-school graduation grade. This is in fact the case. The nonparametric Spearman rank correlation coefficient is positive and significant at any conventional level $(\mathrm{p}<.0001)$. However, it could be argued that other variables additional to abilities shape students' aspirations and reference standards. In order to control for these additional factors of influence we asked two sets of control questions (see Table 1). The first set contains socioeconomic variables like sex, age, field of study, community size, disposable income and working hours. The second block of control questions contains eight questions taken from the General Social Survey (GSS) questionnaires. ${ }^{14}$ Here students had to indicate the importance of different reasons to 'get ahead'.

\section{Table 1}

Table 1 presents three ordered probit estimations of students' aspirations (ranging from 4 to 6 in steps of .25). The first model contains only abilities (high-school grade) as an explanatory variable. As can be seen from Table 1, abilities have a positive and highly significant effect. We also calculated the marginal effect of a higher ability on aspirations. For the median aspiration grade of 5 , the marginal effect is 0.17 . This implies that relative to the "average subject", having a better grade at the high school exam increases the probability of having an aspiration grade of 5 by 17 percent. In the second model we include a set of socio-economic control questions. Notice that sign and significance of abilities remain unchanged with a marginal effect of 0.19 .

\footnotetext{
${ }^{13}$ In Switzerland this examination is called "Matura", which is typically taken at the age of 19.

${ }^{14}$ Cf. 1987 ISSP Module: Social Inequality (Qs. 186, 717-730).
} 
Two other variables enter significantly, namely sex and technical department. The negative sign associated with the variable sex indicates that female students have lower aspirations compared to males. ${ }^{15}$ This holds even though female students have slightly higher abilities (better high school grades) than their male colleagues. The observation that women are more modest (or less optimistic) conforms to what has often and consistently been found in related studies (Zuckerman, 1979, Maccoby and Jacklin, 1974). ${ }^{16}$ Our model offers an interesting interpretation for this finding. It may well be the case that females, as compared to males, put relatively more weight on relative comparisons. Put differently, women seem to suffer more from falling behind their reference standard and from having to bear unfavorable comparisons. Our model does in fact predict that the more emphasis individuals lay on relative comparisons (measured by $\theta$ ) the lower their goals and reference standards will be, i.e., $\frac{\partial g_{i}^{*}}{\partial \theta}<0$ (see section 4.1. and appendix). ${ }^{17}$ Suggestive evidence in favor of this interpretation comes from the study by Johansson-Stenman et al. (2002) who find that female respondents have a higher concern for relative standing than males (ibd., Table 7). If it is true that females typically have lower expectations or goals this might also contribute to an explanation for why women react less intense to tournament incentives than men (cf., Gneezy et al., 2003).

The variable technical department measures whether the corresponding student studies a 'technical' subject such as physics, chemistry or mathematics. The other subjects comprise medicine, law, social sciences or humanities. We control for this difference because in Zurich grades are typically lower in the technical departments. Therefore it is not surprising that the corresponding students have significantly lower aspirations - even though they have significantly higher high-school grades (MannWhitney two-sample statistic $(\mathrm{p}<.067$, two sided $))$.

\footnotetext{
${ }^{15}$ Note, however, that splitting the sample for females and males reveals that the effect of ability on aspiration is significantly positive for both females and males. While the coefficient is somewhat higher for females, a regression that interacts the gender dummy with abilities reveals no significant difference between females and males.

${ }^{16}$ Moreover, it is compatible with the negative effect of the 'male dummy' in regressions on happiness (Clark and Oswald, 1996). If males have higher aspirations than women, they should ceteris paribus have lower happiness scores as well (see also section 4.3).

${ }^{17}$ At the same time, however, also $\frac{\partial c_{i}^{*}}{\partial \theta}>0$, i.e. output rises with an increase in $\theta$. This is also compatible with the fact that females typically do slightly better on the final exams, despite the fact that they have lower goals.
} 
The third model includes answers to the question: "Please indicate for all following reasons, how important they are for getting ahead". The answers allow us to further control for possible omitted influences. As shown in Table 1 (Model 3) the coefficient on ability remains basically unchanged and stays highly significant (marginal effect equals 0.20). The same holds for the variables sex and technical department. The only new variable which enters the regression at a conventional level of significance is ambition. The positive sign means that people who think that ambitions are important to get ahead report higher aspiration levels. This is consistent with the view that people who put strong emphasis on self-improvement also put more weight on upward comparison. Finally, the variable well educated parents enters negatively (although with a p-value of only 0.058) which means that students stating that well educated parents are important for getting ahead have lower goals. This result is compatible with the view that people who think that their success is largely determined by forces that are outside of their own control don't have a reason to put much weight on self-improvement goals. Rather they lower their reference standards to serve self-enhancement motives.

\section{Further Implications of Endogenous Reference Standards}

Thus far we have focused on the influence of personal characteristics on the optimal choice of individual goals. In particular we have shown that our simple model predicts that people's goals increase in their abilities and we have presented evidence that strongly supports this central result. The model has, however, further consequences and implications, some of which we want to discuss briefly in this section. First, we will sketch how environmental (rather than personal) factors influence the choice of reference standards in the model and discuss possible implications. We will then proceed to discuss how the possibility of coping more generally changes the direction and intensity of peoples' endeavours and how they perceive their own economic, social and interpersonal situation. This again has important implications for their sense of well-being and furthermore also for their behavior. These aspects are discussed with examples concerning happiness studies and models of migration. 


\subsection{The Role of Environment and Context}

Proposition 1 states how individuals' abilities influence their goal-setting behavior. This, however, is not the only factor in our model that has an impact on the optimal choice of reference standards. The context in which a specific goal-choosing situation is embedded is likely to determine the size of crucial parameters like $q$ (the strength of forced comparisons), $\delta$ (the motivational power of self-improving factors) or $\theta$ (the relative importance of relative vs. absolute outcomes). Problem-related, situational and cultural differences might thus change the incentive structure and lead to different goal-setting behavior and to different outcomes.

For example, in the context of our empirical results in section 3 and the fact that women tend to set themselves lower goals we have already commented on the (perceived) impact of $\theta$ on the selected reference standard. The more important relative comparisons are (i.e., the higher $\theta$ ), the higher is the outcome (i.e., $\frac{\partial c_{i}^{*}}{\partial \theta}>0$ ). At the same time the actively chosen component of a person's reference standard $g_{i}^{*}$ and the reference standard $r_{i}^{*}$ decrease in $\theta$ (i.e., $\frac{\partial g_{i}^{*}}{\partial \theta}<0$ and $\frac{\partial r_{i}^{*}}{\partial \theta}<0$ ). The intuition behind this result is as follows. If relative comparisons become more important, people put more weight on their relative outcome, i.e., the outcome relative to the given reference standard. This makes it more valuable to perform better, relative to $r_{i}$. As a consequence, people work harder (increase their efforts $e_{i}$ ) and end up with higher levels of outcome (e.g., consumption). At the same time, people decrease the level of their reference standard as relative comparisons become more important. This means that they insulate themselves from relative comparisons by selecting a lower reference standard or reference group. The decrease in $g_{i}^{*}$, however, is not large enough to allow for an unchanged level in $c_{i}^{*}$ (and in efforts $e_{i}^{*}$ ). Although both $g_{i}^{*}$ and $r_{i}^{*}$, decrease, the total impact on the relative outcome component $\left(\theta r_{i}^{*}\right)$ is still strong enough to cause an increases in optimal outcome and effort. We do not want to extend our conclusions too far since the model on which they are based is admittedly quite simple. Nevertheless we want to mention that as an implication of this result one would predict, e.g., that in societies where people put more emphasis on relative comparisons, people work harder and reach a higher outcome. 


\subsection{Happiness Studies}

The possibility of coping captured in the model is helpful to interpret some regularities from happiness studies that cannot easily be explained by more standard approaches. For example it is typically observed in these studies that a majority of respondents indicates a high level of happiness ("happy" or "very happy"; see, e.g., Clark and Oswald, 1996). We speculate that the use of coping strategies is among other factors - responsible for this finding. This is so because people tend to compare themselves to similar others which contributes to insulating themselves from unfavorable comparisons and dissatisfying situations.

As a second example we want to refer to the fact that happiness studies often show that highly educated people are less satisfied with their job (Clark and Oswald, 1996). A lower job satisfaction for higher educated people is not easily explained if the assumption of exogenously given comparison levels is maintained. A natural way to interpret these data, however, is in terms of our model, i.e., that reference standards vary with individual characteristics such as education or ability. In fact this is how Clark and Oswald interpret their data. They note that the negative impact of education on reported satisfaction "may be consistent with the view that utility depends on the gap between outcomes and aspirations, and that education raises aspiration targets" (Clark and Oswald, 1996, 360-361).

\subsection{Migration}

The previous example referred to the fact that reference groups and standards will shape the degree of satisfaction with a situation and that the possibility of coping is likely to have an impact on this perception. It will therefore also influence people's behavior in fields where it is frequently argued that a concern for relative standing plays an important role. These include, e.g., studies on the outbreak of social unrest and political violence, the engagement in illegal activities (crime), voting behavior or migration. The active use of coping strategies - emphasized in our model — enables people to shield themselves from too unfavorable comparisons which might reduce to a certain extent the importance of relative deprivation in the above mentioned areas.

We want to discuss this somewhat more extensively for the theory of (im)migration (cf. Borjas, 1994). In a strictly neoclassical migration model where people care only about their absolute well-being and not about their relative position in society (i.e., 
$\theta=0)$ an individual will migrate to a richer country whenever he expects to earn a higher wage there, independent of his respective relative position in the new society. This, however, is no longer true if one assumes that people also care about their relative standing (cf. Stark and Taylor, 1991). In most cases immigrants have to accept a fall in their relative position in the country of destination ${ }^{18}$ and thus they are confronted with a trade-off: an increase in absolute income is associated with a fall in the relative position.

Sometimes it is even maintained that people will only migrate to another country if this is not associated with a deterioration of their relative position (cf. the "relative deprivation hypothesis", Stark and Taylor, 1991, p. 1164f.). In the light of our model, however, this view has to be qualified. First, people do not care solely about their relative standing (i.e., $\theta<1$ ) and, second, they often have the possibility to cope and to adjust their reference group to their income rank (i.e., $q>0$ ). One can show that in the case of perfect coping (i.e., $q=1$ ) our reference standard model of migration coincides with the neoclassical theory. In this case individuals can shield themselves from any unfavorable comparison and they will thus migrate as long as they earn higher wages in the destination country than they earn in the source country. ${ }^{19}$

The migration example illustrates that it is important to know how people find and form their reference standards and how they deal with situations that are unfavorable for themselves. The possibility of coping might lead to a situation that is indistinguishable from the neoclassical model, despite the fact that people undertake comparisons. Empirical studies should thus also consider the possibility of coping and of endogenous and heterogenous reference groups.

The basic intuition of our migration example carries over to other applications like the study of social unrest. If people optimally select reference standards they can protect themselves from too unfavorable comparisons. This reduces discontentment with the present situation and improves social stability. As a consequence the outbreak of social unrest is rather unlikely even if income is quite unequally distributed

\footnotetext{
${ }^{18}$ This might be due to factors like mismatch of abilities, lack of country-specific human capital and education, discrimination or higher unemployment rates among immigrants. All these factors may decrease the average (or expected) hourly wages (cf. Borjas, 1994, p. 1685f.).

${ }^{19} \mathrm{~A}$ formal treatment of this result is included in a previous version of this paper. Another mechanism, which is likely tobe important for the migration decision is comparison with one's own past income. Migrants probably do not only compare themselves with others but also with their own past.
} 
and even if people compare themselves with others. ${ }^{20}$

\section{Conclusion}

In this paper we have presented a model which allowed us to discuss how people with certain abilities choose their goals and reference standards in an optimal way, high enough to elicit effort and low enough to prevent unnecessary feelings of failure and deprivation. The model predicts that reference standards increase in individuals' abilities which in turn implies that people compare themselves to similar others. We have provided empirical evidence that abilities do in fact shape goals and reference standards and we have argued that various empirical regularities conform to the perspective advocated in this paper. Furthermore we have discussed how models that allow for the possibility of coping might be useful for various fields of economic study.

An approach that is related to the arguments presented in this paper is the habit formation approach that also implies heterogenous reference standards and can be used to explain some of the empirical regularities outlined above. There is no doubt that past performance is an important determinant for people's reference standards. The main difference to the coping approach suggested in this paper, however, concerns the passive nature of the habit formation process, which neglects the importance of influencing and shaping the own reference standard.

In contrast our paper stresses the active role people play in selecting comparison targets. Allowing people to choose their Joneses does not mean that comparison becomes completely arbitrary, however. As we have shown in our simple theoretical framework, the 'optimal Joneses' depend on the specific dimension of comparison, the context of the comparison situations and on individually different characteristics, such as abilities.

\footnotetext{
${ }^{20}$ Cf. on this topic, for example, Rainwater (1974) and MacCulloch (1999).
} 


\section{Appendix - Derivations and Proofs}

Each individual maximizes the utility function (3) subject to (2). The (earnings) ability $a_{i}$ is different between individuals and is the only kind of heterogeneity in our model. We assume that the individual treats $x$ as being independent of his own decision (i.e., for the case where $x=\bar{c}$ he sets $\frac{\partial \bar{c}}{\partial c_{i}}=0$ ). Substituting for $e_{i}$ the maximization problem becomes:

$$
\max _{\left\{c_{i}, g_{i}\right\}} u_{i}=\alpha \ln \left(c_{i}-\theta(1-q) x-\theta q g_{i}\right)+\beta(1-\delta) \ln \left(1-\frac{c_{i}}{a_{i}}\right)+\beta \delta \gamma \ln \left(g_{i}\right),
$$

where $\gamma \equiv q \theta$. The first order conditions are:

$$
\begin{gathered}
\frac{\partial u_{i}}{\partial c_{i}}=\frac{\alpha}{c_{i}-\theta(1-q) x-\theta q g_{i}}-\frac{\beta(1-\delta)}{a_{i}-c_{i}}=0 \\
\frac{\partial u_{i}}{\partial g_{i}}=-\frac{\alpha \theta q}{c_{i}-\theta(1-q) x-\theta q g_{i}}+\frac{\beta \delta \gamma}{g_{i}}=0
\end{gathered}
$$

For $\theta>0$ and $q>0$ we can use these equations to derive the equilibrium values (denoted by "stars") of the main variables:

$$
\begin{gathered}
c_{i}^{*}=\frac{\alpha+\beta \delta \gamma}{\mu} a_{i}+\frac{\beta(1-\delta) \theta(1-q)}{\mu} x \\
g_{i}^{*}=\frac{\beta \delta}{\mu} a_{i}-\frac{\beta \delta \theta(1-q)}{\mu} x \\
r_{i}^{*}=(1-q) x+q g_{i}^{*}=\frac{(1-q)(\alpha+\beta(1-\delta))}{\mu} x+\frac{\beta \delta q}{\mu} a_{i}
\end{gathered}
$$

where $\mu \equiv \alpha+\beta(1-\delta)+\beta \delta \gamma$. If we make the assumption that $x=\bar{c}$ then it holds in equilibrium that $\int_{i=0}^{1} c_{i}\left(\bar{c}^{*}\right) \mathrm{d} i=\bar{c}^{*}$. Using this aggregation condition we can derive:

$$
\bar{c}^{*}=\frac{\alpha+\beta \delta \gamma}{\alpha+\beta(1-\delta)[1-\theta(1-q)]+\beta \delta \gamma} \bar{a}
$$

where $\bar{a}=\int_{i=0}^{1} a_{i} \mathrm{~d} i$ denotes the average level of abilities in the considered group. ${ }^{21}$ We assume throughout the paper that $a_{i} \geq \theta(1-q) \bar{c}^{*}=\frac{\theta(1-q)(\alpha+\beta \delta \gamma)}{\alpha+\beta(1-\delta)[1-\theta(1-q)]+\beta \delta \gamma} \equiv \tilde{a}, \forall i$, which guarantees that the income distribution is sufficiently compressed. ${ }^{22}$

\footnotetext{
${ }^{21}$ For the cases where $\theta=0$ and/or $q=0$ the equilibrium values for $c_{i}^{*}$ and $\bar{c}^{*}$ are still given by (6) and (9), respectively. But, as argued above, the personal goal $g_{i}$ is an irrelevant and void concept in these cases and therefore one cannot state an equilibrium value for it. Similarily for $\theta=0$ the reference standard $r_{i}^{*}$ is not defined while for $q=0$ it is given by $r_{i}^{*}=\bar{c}^{*}$ (which can be seen also from (8)).

${ }^{22}$ This guarantees that in equilibrium $c_{i}^{*}-\theta r_{i} \geq 0, g_{i}^{*} \geq 0$ and $0 \leq e_{i}^{*} \leq 1, \forall i$.
} 
Proposition 1: Using (7), (8) and (6) we can derive: $\frac{\partial g_{i}^{*}}{\partial a_{i}}=\frac{\beta \delta}{\mu}>0, \frac{\partial r_{i}^{*}}{\partial a_{i}}=\frac{\beta \delta q}{\mu}>0$ and $\frac{\partial c_{i}^{*}}{\partial a_{i}}=\frac{\alpha+\beta \delta \gamma}{\mu}>0$.

Using the same relations we can show that:

$\frac{\partial c_{i}^{*}}{\partial \theta}=\frac{\beta(1-\delta)}{\mu^{2}}\left[\beta \delta q a_{i}+(\alpha+\beta(1-\delta))(1-q) \bar{c}^{*}+\theta(1-q) \mu \frac{\partial \bar{c}^{*}}{\partial \theta}\right]>0$ since $\frac{\partial \bar{c}^{*}}{\partial \theta}=$ $\frac{\beta(1-\delta)(\alpha(1-q)+\beta \delta q)}{(\alpha+\beta(1-\delta)[1-\theta(1-q)]+\beta \delta \gamma)^{2}} \bar{a}>0$. Since $\frac{\partial g_{i}^{*}}{\partial \theta}=-\frac{\delta}{1-\delta} \frac{\partial c_{i}^{*}}{\partial \theta}$ we can also conclude that: $\frac{\partial g_{i}^{*}}{\partial \theta}<0$. 
Table 1 - Ordered Probit Estimates of Aspired Grade at the Final University Examination ${ }^{\dagger}$

\begin{tabular}{|c|c|c|c|}
\hline & Model 1 & Model 2 & Model 3 \\
\hline High School Grade (ability) & $\begin{array}{l}.742 * * \\
(.171)\end{array}$ & $\begin{array}{l}.804 * * \\
(.180)\end{array}$ & $\begin{array}{l}.832 * * \\
(.185)\end{array}$ \\
\hline Sex & & $\begin{array}{c}-.385^{* *} \\
(.147)\end{array}$ & $\begin{array}{c}-0.422 * * * \\
(.151)\end{array}$ \\
\hline Age & & $\begin{array}{l}-.005 \\
(.027)\end{array}$ & $\begin{array}{c}.002 \\
(.027)\end{array}$ \\
\hline Technical Department & & $\begin{array}{c}-.475^{* *} \\
(.150)\end{array}$ & $\begin{array}{c}-.494 * * \\
(.153)\end{array}$ \\
\hline Native & & $\begin{array}{l}-.127 \\
(.221)\end{array}$ & $\begin{array}{l}-.206 \\
(.228)\end{array}$ \\
\hline Community Size & & $\begin{array}{l}-.069 \\
(.077)\end{array}$ & $\begin{array}{l}-.095 \\
(.079)\end{array}$ \\
\hline Money Available & & $\begin{array}{c}.000 \\
(.000)\end{array}$ & $\begin{array}{l}.000 \\
(.000)\end{array}$ \\
\hline Working Hours & & $\begin{array}{c}.004 \\
(.012)\end{array}$ & $\begin{array}{c}.003 \\
(.012)\end{array}$ \\
\hline Wealthy Family Background & & & $\begin{array}{c}.020 \\
(.052)\end{array}$ \\
\hline Well Educated Parents & & & $\begin{array}{l}-.113 \\
(.059)\end{array}$ \\
\hline Good Own Education & & & $\begin{array}{c}.002 \\
(.100)\end{array}$ \\
\hline Ambitions & & & $\begin{array}{l}.175^{*} \\
(.084)\end{array}$ \\
\hline Natural Talents & & & $\begin{array}{c}.042 \\
(.063)\end{array}$ \\
\hline Hard Work & & & $\begin{array}{l}-.105 \\
(.063)\end{array}$ \\
\hline Knowing the Right People & & & $\begin{array}{l}-.030 \\
(.066)\end{array}$ \\
\hline Political Connections & & & $\begin{array}{c}.048 \\
(.056)\end{array}$ \\
\hline $\mathrm{N}$ & 255 & 249 & 249 \\
\hline Log likelihood & -406.833 & -386.600 & -381.619 \\
\hline Prob $>$ chi 2 & .000 & .000 & .000 \\
\hline
\end{tabular}

\footnotetext{
"Note: standard errors in parentheses; $*=$ significant at the 5-percent level; ** $=$ significant at the 1-percent level; Sex: $1=$ female, $0=$ male; Technical Department: $1=$ yes, $0=$ no; Native: $1=$ swiss, $0=$ not Swiss; Community size $1=$ up to 2.000 inhabitants, $2=2.000$ to 10.000 inhabitants, $3=10.000$ to 100.000 inhabitants, $4=$ more than 100.000 inhabitants; Money available: Money for living net rent (monthly); Working hours: Hours worked net hours for study (weekly); The additional variables in model 3 are taken from the GSS-survey. The question was: "Please indicate for all following reasons, how important they are for getting ahead." Answers are coded in the following way: $1=$ not at all important, $2=$ not very important, $3=$ don't know, $4=$ important, $5=$ =pretty important, $6=$ very important. In models 2 and 3 the number of observations is smaller due to missing answers.
} 


\section{References}

Affleck, G. and Tennen, H. (1991), "Social comparison and coping with major medical problems", in: Suls, J. and Wills, T. A. (eds.), Social comparison: Contemporary theory and research, New Jersey: Lawrence Erlbaum Associates, Inc., Publishers, 237-260.

Bandura, A. (1986), "Social foundations of thought and action: A social cognitive theory, Englewood Cliffs", NJ: Prentince-Hall.

Borjas, G. (1994), "The economics of immigration", Journal of Economic Literature, 32(4), $1167-1717$.

Boskin M. J. and Sheshinski, E. (1978), "Optimal redistributive taxation when individual welfare depends on relative income“, Quarterly Journal of Economics, 92(4), 589-601.

Brown, J. D. and Dutton, K. A. (1995), "Truth and Consequences: The Cost and benefits of accurate self-knowledge", Personality and Social Psychology Bulletin, 21(2), 1288-1296.

Campbell, J. D. (1986), "Similarity and uniqueness: The effects of attribute type, relevance, and individual differences in self-esteem and depression", Journal of Personality and Social Psychology, 50, 281-294.

Campbell, J. Y. and Cochrane, J. H. (1999), "By force of habit: A consumption-based explanation of aggregate stock market behavior”, Journal of Political Economy, 107(2), 205-51.

Carroll, C. D. (1998), “Why do the rich save so much?”, NBER Working Paper No.: 6459.

Clark, A. E. and Oswald, A. J. (1996), "Satisfaction and comparison income“, Journal of Public Economics, 61(3), 359-381.

Cooper, B. and Garcia-Penalosa, C. (1999), "Status effects and negative utility growth", Nuffield College Discussion paper No. 150.

Diener E. and Fujita, F. (1997), "Social comparison and subjective well-being", in Health, coping and well-being, edited by B. P. Buunk and R. Gibbons, Mahwah, NJ: Erlbaum.

Easterlin, R. A. (1974), "Does economic growth improve the human lot? Some empirical evidence", 89-125 in: David, P. and Reder, M. (eds.), Nations and households in economic growth: Essays in honor of Moses Abramovitz, Stanford University Press. Stanford, CA.

Easterlin, R. A. (1995), "Will raising the incomes of all increase the happiness of all?", Journal of Economic Behavior and Organization, 27(1), 35-47.

Frank, R. H. (1985), "Choosing the right pond. Human behavior and the quest for status", Oxford University Press: New York and Oxford.

Gneezy, U., Niederle, M. and Rustichini, A. (2003), "Performance in competitive environments: Gender Differences," Quarterly Journal of Economics, CXVIII, 1049 1074.

Johansson-Stenman, O., Carlsson, F. and Daruvala, D. (2002), "Measuring future grandparents' preferences for equality and relative standing", The Economic Journal, 112 (April), 362-383.

Knell, M. (1999), "Social comparisons, inequality, and growth", Journal of Institutional and Theroetical Economics, 112(4), 664-695.

MacCulloch, R. (1999), "What makes a revolution“, ZEI Working Paper, B24.

Maccoby, E. E. and Jacklin, C. N. (1974), "The psychology of sex differences", Stanford, CA: Stanford University Press.

Major, B., Testa, M. and Bylsma, W. H. (1991), "Responses to upward and downward social comparisons: The impact of esteem-relevance and perceived control", in: Suls, J. and Wills, T. A. (eds.), Social comparison: Contemporary theory and research, New Jersey: Lawrence Erlbaum Associates, Inc., Publishers, 237-260.

Marks, G. (1984), “Thinking one's are unique and one's opinions are common”, Personality and Social Psychology, 45, 384-393. 
Neumark D. and Postlewaite, A.(1998), "Relative income concerns and the rise in married women's employment", Journal of Public Economics, 70(1), 157-83.

Rainwater, L. (1974), "What money buys", New York: Basic Books.

Seta, J. (1982), "The impact of comparison processes on coactors' task performance", Journal of Personality and Social Psychology, 42, 281-291.

Stark, O. and Taylor, J. E. (1991), "Migration incentives, migration types: The role of relative deprivation”, Economic Journal 101(408), 1163-1178.

Taylor, S. E., Wood, J. V. and Lichtman, R. R. (1983), "It could be worse: Selective evaluations as a response to victimization", Journal of Social Issues, 39, 19-40.

Wills, T. A. (1981), "Downward Comparison principles in social psychology", Psychological Bulletin 90, 245-271.

Wood, J. V. and Taylor, K. L. (1991), "Serving self-relevant goals through social comparison", in: Suls, J. and Wills, T. A. (eds.), Social comparison: Contemporary theory and Research, New Jersey: Lawrence Erlbaum Associates, Inc., Publishers, 23-49.

Zuckerman, M. (1979), "Attribution of success and failure revisited, or: The motivational bias is alive and well in attribution theory", Journal of Personality 47, 245-287. 